\title{
MEMÓRIA E IDENTIDADE POTIGUAR EM REDE: UMA EXPERIÊNCIA REALIZADA A PARTIR DE MÍDIAS DIGITAIS
}

\author{
P. M. P. CAPISTRANO ${ }^{1}$, W. OLIVEIRA ${ }^{2}$, M. A. S. FERNANDES ${ }^{3}$, S. G. P. SOUZA ${ }^{4}$, M. P. C. ASSIS ${ }^{5}$ \\ 1, 2, 3,4 e 5 Instituto Federal de Educação, Ciência e Tecnologia do Rio Grande do Norte \\ pablo.capistrano@ifrn.edu.br -wagner.oliveira@ifrn.edu.br - aparecida.fernandes13@yahoo.com.br - \\ suely.gleide@ifrn.edu.br - michelle.pinheiro@ifrn.edu.br
}

Artigo submetido em novembro/2011 e aceito em dezembro/2011

\section{RESUMO}

O presente artigo foi construído a partir do projeto de extensão Portal de Cultura Potiguar, coordenado pelos professores autores. O projeto foi realizado no ano de 2010 na região do Trairi potiguar e consistiu no mapeamento e na gravação de depoimentos de artistas da região que falavam sobre a sua própria produção artística e cultural, bem como na feitura de um portal virtual, vinculado ao site do Instituto Federal de Educação, Ciência e Tecnologia do Rio Grande do Norte-IFRN, a fim de divulgar o material recolhido para a comunidade de alunos, bem como para pesquisadores e público externo. Em função da crise instituída a partir da falência dos modelos teóricos de compreensão da cultura popular no Rio Grande do Norte, bem como das mudanças sociais, políticas e econômicas nos últimos anos do século $X X$, que tornaram Natal o centro urbano mais importante do Estado, noções como identidade, memória e cultura potiguar começaram a sofrer profundas reformulações. Essas reformulações podem ser percebidas na produção dos artistas potiguares. O uso de novas mídias como a Internet como um mecanismo de integração cultural pode contribuir para uma nova compreensão do papel da memória e das expressões culturais do Estado na construção de um tipo dinâmico de identidade potiguar, que dê conta das demandas de nosso tempo.

PALAVRAS-CHAVE: Arte, Memória, Identidade Potiguar, Internet, Novas mídias.

\section{MEMORY AND IDENTITY POTIGUAR IN NETWORK: An experiment performed from digital media}

\begin{abstract}
This article was constructed from the extension project Potiguar Culture Portal, coordinated by professors authors. The project was conducted in 2010 in the region of Trairi potiguar and consisted of mapping and recording of testimony from local artists who talked about their own cultural and artistic production, as well as in making a virtual portal, linked to the site Federal Institute of Education, Science and Technology-Rio Grande do Norte IFRN in order to disseminate the material collected for the community of students, as well as for researchers and general public. Due to the crisis established from the failure of theoretical models
\end{abstract}

of understanding of popular culture in Rio Grande do Norte, as well as social, political and economic in the last years of the twentieth century that made Natal the most important urban center of the state, notions of identity, memory and culture RN began to suffer deep reformulation. These reformulations can be seen in the production of potiguares artists. The use of new media like the Internet as a mechanism of cultural integration can contribute to a new understanding of the role of memory and cultural expressions of the state in building a dynamic type of identity Natal, which meet the demands of our time.

KEY-WORDS: Art, Memory, Identity Potiguar, Internet, New Media. 


\section{O ENSINO DE TEATRO NOS CURSOS TÉCNICOS INTEGRADOS DO IFRN}

\section{INTRODUÇÃO}

Este artigo visa a, a partir da experiência de produção do Portal de Cultura Potiguar, discutir a introdução das mídias digitais como veículos de integração cultural e de construção da memória e da identidade sócio-cultural potiguar em um sentido diverso do que foi desenvolvido a partir do advento das redes de TV aberta no início dos anos de 1980, bem como a partir de pressupostos diversos daqueles que tradicionalmente condicionaram os estudos teóricos sobre a cultura popular no Rio Grande do Norte.

O Estado teve como traço histórico e geográfico um povoamento realizado pelos extremos. As áreas mais densamente povoadas, onde se concentram as maiores cidades situam-se no litoral leste (região da grande Natal), no Oeste (Mossoró e Pau dos Ferros) ou na região do Seridó (Caicó e Currais Novos) próximas à fronteira com o Estado da Paraíba. As regiões centrais do Estado não foram largamente povoadas, produzindo um quadro de pouca interação cultural entre a Região Oeste, o Litoral leste e o Seridó, ao sul. Nesse sentido, a cidade de Mossoró e a região das serras (chamada de Tromba do Elefante) teve seu desenvolvimento sócio-econômico ligado às cidades de Aracati e Fortaleza, bem como ao vale do rio Jaguaribe no Ceará. O Seridó, por sua vez, pertencente à Paraíba até o ano de 1821 (AUGUSTO, 1954), teve seu desenvolvimento atrelado de maneira significativa à região do "brejo paraibano", responsável pela conexão entre o Sertão e o litoral no Estado da Paraíba (MELLO, 2002).

Esse quadro de povoamento se dá por razões históricas bem definidas. Ao contrário de Pernambuco, da Paraíba ou do Ceará, que desde o tempo colonial desenvolveram em suas capitais, pólos urbanos que atuavam como centros de síntese cultural, econômica e política, o Rio Grande do Norte desenvolveu-se até os anos 80 do século passado como um estado cindido em três esferas de influência divergentes (TRINDADE, 2007). A grande Natal, padecendo de certo isolamento geográfico, submetida economicamente às cidades de Macaíba (onde se localizava o porto que escoava a produção algodoeira do sertão) e Ceará Mirim (RODRIGUES, 2003), até os últimos anos do século XX esteve presa à área de influência de Recife e não tinha força social, urbana ou populacional para atuar como uma síntese das metades cindidas do Estado.

Esse quadro geográfico, econômico e histórico fez com que o Rio Grande do Norte se desenvolvesse sem um fortalecimento de laços firmes de identidade que marcassem um sentimento de "potiguaridade", de modo a unir esses três núcleos culturais mais importantes do Estado. Isso começou a mudar no final dos anos 70, com a chegada das redes de TV aberta. Inicialmente, a TV Universitária - TVU e, posteriormente, a Rede Cabugi, o SBT, a Rede Bandeirantes. A chegada das mídias eletrônicas, com programas locais e com a retransmissão dos telejornais diários a partir de Natal, produziu o início de um processo de integração cultural que fortaleceu a posição de Natal como centro de produção e divulgação da cultura potiguar.

Nesse sentido, o processo de construção de uma "identidade potiguar" se apresenta atualmente fortemente centralizado na capital, que hoje atua como um núcleo econômico, político e 
cultural do RN. Esse padrão de construção de eixos culturais segue o modelo de uso das mídias televisivas, que são unidirecionais e que funcionam em um sistema de emissor-receptor de baixa interatividade.

Sob esse aspecto, a construção do Portal de Cultura Potiguar, por meio do projeto de Extensão implementado inicialmente pelo IFRN - Campus Santa Cruz, e que posteriormente (2011) expandiu-se para o IFRN Zona Norte, busca o desenvolvimento de outro modelo de integração cultural que passe pela adoção de novas mídias como a INTERNET e as Redes Sociais. A experiência de construção do Portal de Cultura Potiguar mostra a pertinência de se utilizarem mídias multipolares, a partir de uma experiência de construção multifocal em rede que permita um conjunto de ações de divulgação cultural, bem como uma maior interatividade que permita às diversas regiões do Estado do Rio Grande do Norte desenvolverem uma integração marcada pela maior descentralização e pela horizontalidade da comunicação.

\section{CULTURA POTIGUAR, UM CONCEITO ABERTO}

Os estudos sobre as manifestações populares e a identidade cultural potiguar foram muito influenciados pelas ideias e pelos trabalhos de Luiz da Câmara Cascudo, o qual ajudou a construir uma imagem de Nordeste que influenciou profundamente os estudos sociais e antropológicos que se debruçaram sobre as identidades regionais nos diversos estados da federação. Câmara Cascudo, como mostra Durval Muniz de Albuquerque Junior (2009), definiu a imagem da cultura brasileira, nordestina e potiguar a partir de referenciais teóricos extraídos de estudiosos ibéricos, mais especificamente espanhóis. No corpo do cânone de referências usadas por Cascudo, destacam-se teóricos que começaram a desenvolver seus estudos sobre cultura popular a partir do ano de 1870 (ALBUQUERQUE JUNIOR, 2003). Estudiosos e literatos como Almeida Garret, Alexandre Herculano, Theóphilo Braga, José Leite de Vasconcelos, Jaime Cortesão, Marcelino Menendez y Pelayo, Ramon Menédez Pidal, Francisco Rodriguez Marin, Luís de Hoyos Saínz são alguns dos nomes que compõem o universo de recursos teóricos da biblioteca cascudiana. Como mostra Durval Junior, Cascudo partilhava com esses autores a ideia de uma busca de um "retorno ao passado" e de uma procura por antigas formas sociais, políticas e culturais que pudessem servir como elemento de reconstrução de um antigo ethos perdido, dissolvido pelo advento das revoluções modernas e do capitalismo industrial (ALBUQUERQUE JUNIOR, 2009, p. 195).

Neste sentido, Cascudo mantinha, com o catolicismo militante e com certo monarquismo nostálgico, um poderoso vínculo ideológico, que condicionava sua visão de cultura popular e que ajudou a construir o enfoque dado pelos estudos culturais no Rio Grande do Norte. Ideias extraídas do romantismo germânico, que curiosamente foram utilizadas também no ideário nazi-fascista, como de "espírito do povo" (Volksgeist ${ }^{1}$ ) ou "espírito do tempo" (Zeitgeist), unidas à noção de uma "ameaça da

\footnotetext{
${ }^{1}$ A palavra Geist em alemão tem um sentido amplo. Tanto pode fazer referência a ideia de espírito como em Heiligegeist (Espírito Santo), quanto de "cultura". Sob esse aspecto o termo Volksgeist, traduzido por alguns como espírito do povo, pode também ser lido como "cultura popular". O uso da palavra Geist com o sentido de
} 
modernidade" que poderia destruir as identidades nacionais na Espanha (formada tradicionalmente a partir de quatro grandes nichos linguísticos e culturais: Basco, Castelhano, Catalão, Galego), foram transferidas para a realidade brasileira através do regionalismo nordestino, que influenciou não apenas Cascudo, mas autores como Gilberto Freyre e, posteriormente, Ariano Suassuna. O fim das particularidades regionais, ligadas a matrizes culturais tradicionais, se conectava, desse modo, a uma visão romântica de um passado glorioso, ligado a um universo senhorial e aristocrático que seria decomposto com as revoluções burguesas e com o advento da modernidade industrial e urbana.

Essa conjuntura teórica liga a tradição de interpretação cultural cascudiana ao salazarismo e ao franquismo ibéricos, bem como aos ideários culturais que serviram ao Integralismo brasileiro. Como atesta Durval de Albuquerque Junior (2009, p. 197), "Cascudo demonstra clara simpatia pelas posições de autores Espanhóis" que construíram uma visão de tradição cultural e de identidade nacional, católica, fincada na ideia de um passado de glórias perdido pela contaminação e pela introdução de elementos externos. Essa nostalgia, essa saudade de um tempo glorioso perdido, de um mundo destroçado ou em vias de extermínio, marcou e ainda marca profundamente a postura dos estudos sobre a cultura popular no Estado do Rio Grande do Norte.

O "povo" é visto como um elemento de resistência e de conservação de formas sociais ameaçadas pela mudança social e tecnológica que a economia de mercado impõe sobre os países ibéricos, bem como sobre o Brasil. A preservação da pureza popular implica, deste modo, uma crítica à adoção de novas tecnologias e ao avanço do mundo urbano. O poder revolucionário das massas populares, elemento fundamental do pensamento marxista é substituído por uma noção aristocrática e conservadora de "cultura popular" influenciada pelo catolicismo tradicional espanhol: "A proximidade entre a forma como Cascudo pensa o Povo e a cultura popular e a forma como os pensam os folcloristas e etnólogos espanhóis do século XIX se deve justamente ao fato de compartilharem uma interpretação que tem como inspiração as teses da Igreja Católica". (ALBUQUERQUE JUNIOR, 2009 p. 208).

Menéndez y Pelayo, segundo Durval Junior (2009), frequentemente citado nas obras de Cascudo, era um dos representantes da direita católica espanhola que, como representante da erudição, ligada ao movimento da Restauração Espanhola, buscou constantemente unir em seu trabalho aspectos profundamente religiosos do catolicismo ibérico com uma hermenêutica historicista influenciada pelos trabalhos de autores que partiram dos escritos de filósofos da geração romântica alemã (GONDRIN, 2003). Esse enfoque perpassa não apenas a construção da ideia de uma identidade potiguar, mas, fundamentalmente, toda a construção da ideia de Nordeste como pensada pelo regionalismo dos anos de 1930.

Somada a essa reação católica à modernidade, patrocinada pela genialidade conservadora de um Câmara Cascudo, uniu-se certa reação à presença norte-americana em Natal, que veio também a definir o ideário cultural da esquerda potiguar. Podemos tomar como ícone desse segundo movimento, de origem também, nos grupos políticos das comunidades de base da Igreja Católica, a

cultura foi adotado pelo romantismo alemão como uma forma de reação nacionalista a outro termo Kultur, de origem latina. 
gestão do prefeito Djalma Maranhão em Natal, que valorizou sobremaneira as manifestações da cultura popular, reforçando a noção de uma identidade potiguar como elemento de fortalecimento das classes trabalhadoras (GÓES, 1980).

As origens dessa tendência na capital podem estar fincadas no período da chegada dos norte americanos à cidade durante a Segunda Guerra. Longe de ter sido um momento de integração pacífica ou mesmo de subordinação e adesão incondicional à cultura estrangeira na cidade de Natal, como pensam alguns e como se divulga aqui e acolá em tese de explicar a aparente "estrangeirização" da cultura de Natal, a presença dos norte-americanos em solo potiguar lançou o embrião de instituições e movimentos de resistência cultural.

Como observa Flávia de Sá Pedreira (2009), na capital, "a ideia de resistência aos elementos exógenos no campo da cultura manifesta-se de modo mais intenso a partir do período da Guerra, com a criação, com sede no Alecrim, da Federação de Folguedos Tradicionais" (PEDREIRA, 2009, p. 229), que organizava fandangos e pastoris para as Festas da Igreja São Pedro e que atuava junto à Federação Carnavalesca Potiguar, como um tipo de resposta, ou esforço de resistência à influência de setores "americanófilos" da cultura e da intelectualidade do Estado: "Era como se a população potiguar tivesse de se opor às influência exógenas, armando-se nas trincheiras das manifestações culturais locais/nacionais. Entende-se que, em decorrência disso, o Carnaval passou a ser a festa escolhida para melhor resguardar o locus da cultura brasileira naquele momento [...]" (PEDREIRA, 2009, p. 230).

Essas duas forças ideológicas, o "antiamericanismo" de esquerda e o integralismo católico de direita, se uniram sobre um foco comum de entendimento dos aspectos da identidade potiguar e da cultura popular no Estado. Ambos acabam por compreender as expressões de identidade cultural como elementos de permanência e de resistência e não como instâncias de transformação e mudança. o "povo potiguar" como o "povo nordestino", em sua pureza, é visto como uma frágil peça em processo de desconstrução, ameaçado pelos ventos da mudança sócio-econômica e necessitado de um tipo particular de proteção institucional que os livre, como riograndenses do norte, das ameaças exteriores.

Essa visão romântica, quer esteja ela na direita ou na esquerda, contribuiu muito mais para um descolamento das expressões de cultura popular da dinâmica das mudanças econômica e social que tomaram conta do RN, na medida em que a capital Natal começou seu vertiginoso processo de expansão urbana a partir dos anos 70 do século passado.

Na medida em que o crescimento urbano de Natal, movido pela indústria do turismo e da construção civil, bem como pela migração do interior, de outros estados da federação e de vários países do mundo, explodiu nos anos de 1980, a tradicional tripartição cultural do estado (Oeste, Seridó e Agreste) começou a se fragilizar, no momento em que a cidade de Natal inicia-se a despontar como centro urbano mais importante do Estado.

O que este artigo sustenta é que, na medida em que o eixo urbano e populacional do Estado deslocou-se para Natal, motivado em muito pela decadência da economia algodoeira no Seridó e no Oeste, acabou empurrando as populações sertanejas para o litoral. Esse processo acabou levando as 
velhas formas de se compreender a identidade potiguar (tanto as da direita integralista, quanto as da esquerda antiamericana) a uma crise.

Antes de fazer um juízo de valor sobre essa crise, é importante compreender que o conceito de identidade potiguar, ao contrário do que ocorre com outros estados nordestinos nos quais o processo social de integração sertão-litoral seguiu outras características (como Pernambuco e Paraíba) é hoje, mais do que nunca, um conceito aberto. Como um conceito aberto, é importante entendê-lo em construção e reformulação e não como um dado fixo, imutável, uma sombra que paira sobre as fantasias ideológicas de velhos eruditos.

\section{PORTAL DE CULTURA POTIGUAR NO TRAIRI: UMA EXPERIÊNCIA EM REDE}

O projeto Portal de Cultura Potiguar surgiu desta forma, não com a intenção de determinar a partir de alguma visão preestabelecida de cultura popular nascida de pressupostos ideológicos específicos, uma solução para a crise de identidade sócio cultural, por que passa o Estado do Rio Grande do Norte, especialmente a partir de sua capital. Não há uma intenção de "resgate", nem de "preservação" de espécies culturais ameaçadas de extinção no projeto em tela.

O sentido fundamental do projeto é o de construir uma rede de suporte informacional com o recolhimento de depoimentos dos agentes culturais que atuam com as mais diversas expressões artísticas no Estado, sem que seja necessário, para isso, a adoção de uma postura "preservacionista" ou purista dos estudos culturais. Nesse sentido, o recolhimento dos depoimentos dos mestres de cultura entrevistados e a divulgação virtual desses depoimentos tem como objetivo oferecer aos alunos, aos professores do IFRN que trabalham em sala de aula com questões ligadas à construção da memória e das identidades culturais, ferramentas que sirvam como mecanismos didáticos de problematização do próprio conceito de "identidade potiguar". O início do projeto se deu, deste modo, a partir da região do Trairi e do Campus Santa Cruz, tendo em vista o caráter de transição dessa região do Estado.

Os sertões do Nordeste do Brasil foram instituídos a partir de uma cultura que tinha como base econômica a criação de gado (ARAÚJO, 2006). Boa parte das manifestações culturais, literárias e folclóricas tem desse modo, a influência de práticas sociais que giram em torno de hábitos e modos de vida que derivam daquilo que foi chamado por Capistrano de Abreu de "Civilização do couro". A própria configuração política dos sertões do Nordeste se constituiu a partir de relações sociais de vassalagem e dominação que remontam a uma dinâmica social marcada pela relação entre o coronel (líder político, proprietário da terra e do gado) e o vaqueiro.

No Rio Grande do Norte, a influência da cultura do gado se deu de forma bastante significativa no Seridó, ao passo que, no litoral, a influência dos engenhos de cana de Açúcar desenvolveu outras formas culturais e expressões artísticas específicas (CASCUDO, 2009) que instituíram uma cisão psicocultural no estado, pondo de um lado as comunidades sertanejas e de outro as populações do litoral. A essa cisão piscocultural entre litoral-sertão, soma-se a tripartição já tratada em outros tópicos desse artigo, entre Seridó-Oeste-Agreste. 
Nesse sentido, o Trairi se posiciona como uma região de passagem. Uma zona de transição que servia, nas antigas crônicas de viagem, como ponto de referência entre o caminho de Acari para a Capital. A cidade de Santa Cruz, hoje o grande pólo urbano da região, que nasceu a partir de fazendas de gado, ganhou importância como entreposto de hospedagem no caminho entre Acari e Natal (FARIA, 2006). Esse aspecto de zona de transição influenciou em muito, os aspectos mais relevantes da cultura do Trairi, como pode ser visto na presença de elementos litorâneos na tradição de boi Calemba, que ainda se mantém na cidade, especialmente no trabalho de Mestre Antônio da Ladeira.

Do ponto de vista psicocultural a situação geográfica de Santa Cruz acabou por gerar, na atualidade, uma situação peculiar. Muito longe da capital para fazer parte da área de influência da Grande Natal e muito perto para se situar como zona autônoma, Santa Cruz acaba por desenvolver uma curiosa ambivalência na construção de sua própria autoimagem sócio-cultural.

A dificuldade coletiva de percepção dos aspectos identitários de sua própria cultura não é uma exclusividade da região do Trairi (apesar de serem mais notáveis, nesta área, os sintomas dessa crise). O Rio Grande do Norte, como um todo, padece desse tipo de distorção como já foi analisado em outras passagens desse artigo. No entanto, a posição do Trairi em relação ao Seridó e ao Agreste, um lugar de transição e passagem, fazem com que o estado de crise, de indefinição e de ambivalência seja sentida de um modo mais evidente na região.

Importante frisar que o fato de a região do Trairi não ser reconhecida oficialmente pelo IBGE não retira o caráter particular de sua autonomia cultural, bem como o de suas ambivalências especificas. As populações que vivem no curso do Rio Trairi, entre a Serra do Doutor e o Agreste Potiguar trazem marcas de identidades particulares que definem essa região para além das convenções geográficas oficiais. Muitas vezes, entretanto, essas marcas dissolvidas pela influência significativa de aspectos sociais, culturais, políticos e religiosos que emergem da região do Seridó ou do Agreste Potiguar, tornando o Trairi uma área permeável tanto à cultura do litoral quanto a do sertão. Nesse sentido, historicamente, o Trairi se constitui como uma área marcada pelo paradoxo de ter sinais culturais peculiares, sofrendo ao mesmo tempo uma significativa influência da cultura seridoense à oeste e do Agreste a leste. Essa condição de passagem faz com que a população de importantes cidades como Santa Cruz, Tangará, Lages Pintadas, Serra Caiada, Sítio Novo carregam consigo as marcas e reminiscências culturais variadas, que se manifestam no trabalho de seus artistas.

Em Santa Cruz, o projeto mapeou registrou o depoimento e lançou na rede via Portal e Youtube diversos artistas. Entre eles: Mestre Antônio da Ladeira (Boi de Reis); Mestre João Gregório (escultor); Grupo de Teatro Arte Viva; Maestro Deusdete (músico); Marcos Cavalcanti e Hugo Tavares (poetas) e Dona Eudoxia Ribeiro (Romanceira).

Entre esses nomes, o de Dona Eudoxia e de Hugo Tavares mereceram uma especial atenção no sentido de apresentarem de bem marcadamente características que sintetizam um novo foco sobre os aspectos mais tradicionais da cultura do Nordeste em conexão com aspectos históricos e estéticos que atualizam essa tradição. 
Romanceiras como Dona Eudóxia Ribeiro, de Santa Cruz, poetas como Hugo Tavares, no Trairi, ou mesmo grupos de Cultura Popular como o Boi Calemba Pintadinho, de São Gonçalo do Amarante, e o Congo de Guerra, de Ceará Mirim, não são peças de museu. Esses artistas estão vivos, respondendo com sua arte às questões postas pela experiência das suas próprias vidas e do seu entorno, sem perder o fio da tradição. Têm os pés fincados na terra, mas sua criatividade está antenada com o horizonte.

A equipe do Portal teve um exemplo dessa relação de fronteira, que sinaliza conexões entre a tradição e as demandas do presente, ao encontrar com Dona Eudóxia Ribeiro, uma romanceira nascida na Paraíba, mas que reside em Santa Cruz (RN), desde a primeira infância.

O romance de Dona Eudóxia, a despeito de suas formas poéticas tradicionais, com a métrica e a rima que caminham por séculos a partir dos romances medievais, não nos leva, exclusivamente, ao passado.

Em 1953, Dona Eudóxia, que nunca casou nem constituiu sua própria família, concluiu "A Trama da Família Baianos". Ao entrevistá-la, na casa humilde onde morava com a família de um sobrinho, mostrou-nos um de seus cadernos onde escrevia seus poemas, dentro do qual havia algumas fotos de revistas retratando situações de casamento. Ao perguntarmos à romanceira se ela se interessava por histórias de noivas, respondeu-nos: "só quando fogem". É este seu universo. Sem se contentar em repetir as canções que ouvia de outras romanceiras, sem querer apenas reproduzir a tradição que nos conecta com o medievo ibérico, Dona Eudóxia criou sua própria narrativa, seu próprio mito particular, cheio de tropos tradicionais, marcado por histórias que emergem do universo do cordel e do largo inconsciente coletivo dos sertões nordestinos, como as dos ciganos que roubam crianças, das moças raptadas para casar, da luta dos heróicos namorados contra as forças dos pais das donzelas que se opõem ao casamento.

Mas esses velhos tropos dos romances tradicionais aparecem em um mundo tecnológico, cercado de máquinas, aviões, viagens para o estrangeiro, ordens militares, em um cenário que vem de um imaginário radiofônico e cinematográfico que invadia as cidades nordestinas nos anos quarenta e cinquenta.

Como diz Dona Eudóxia, na "Música da raptada":

\author{
"Vou deixar meu lar paterno \\ O berço em que nasci \\ Vou me tornar eremita, papai, \\ Do mundo já desisti \\ Sou frustrada no amor, papai \\ Pois não posso ser feliz.
}


Eu só tenho meu avião

Sei bem ele dirigir

Vou viver pelo espaço

Num vôo eterno, sem fim

Vagando no infinito, papai

É a sina viver assim" (RIBEIRO, 2006).

Marcos Cavalcanti, que prefaciou a única edição em livro desse romance de Eudóxia (publicado em outubro de 2006, 53 anos após ter sido concluído e registrado em cadernos com caneta esferográfica, ilustrado por fotos e recortes de velhas revistas e jornais), afirma, em depoimento à equipe do Portal:

A importância de Eudóxia, ainda, infelizmente não reconhecida e não valorizada, é semelhante à de Dona Militana, uma romanceira muitíssimo conhecida que teve a sorte de ser descoberta por um pesquisador do porte de um Deífulo Gurgel o qual deu visibilidade a ela como intérprete de romance. Dona Eudóxia é do mesmo modo tão importante, porque é escritora de romance.

Se Dona Militana (Romanceira de São Gonçalo) mantinha o romanceiro vivo através de sua voz, Dona Eudóxia faz o mesmo através da releitura de seus tropos retóricos, mantendo-os pulsantes e atuais e criando, em nossa modernidade, um espaço para a permanência, um local para a tradição se reencontrar e se reconfigurar a partir das demandas desse tempo.

Mas renovação da tradição na cultura potiguar não vem apenas das formas literárias populares. Quando, no início do século XX, há, no Brasil, uma apropriação e valorização dos temas rurais pelos músicos da cidade que se fazem apreciar, também, pelo público citadino, verifica-se o sentimento de nação politicamente alimentado pelo advento da República, que suscita um clima de euforia e ebulição social no País. Esse sentimento de nacionalidade, de unidade, traduzida na produção musical, no entanto, passa por uma visão nostálgica, romântica e, de certo modo, alienada do mundo rural ${ }^{2}$. Porém, esse traço que põe em zona de convergência campo-cidade vai se renovando com as várias gerações de músicos - do samba do morro à bossa nova, com a singular batida do violão de João Gilberto, ao pop/tropicalismo - que se põem como intérpretes dos sentimentos populares, dando vazão a uma das nossas vertentes musicais - a música de protesto - cujo auge remonta ao final dos anos 60 .

Essa renovação, entretanto, surge também com a assimilação do dedilhar das cordas dos violeiros do Nordeste e com a permanência, na nossa raiz sonora, do aboio arquetípico, que surge a partir de modos musicais berberes do norte da África e que tempera essa busca do artista pelo seu

${ }^{2}$ TINHORÃO, José Ramos. Pequena história da música popular (da modinha à canção de protesto). Petrópolis: Vozes, 1974. 
próprio povo, por sua identidade, ao mesmo tempo em que dá vazão a seus anseios de liberdade e lhe fornece as ferramentas para que ele responda aos desafios sociais e políticos do sertão do agora.

E é nessa fronteira - a da busca pela liberdade criativa, marca estética da liberdade social e política dos povos sertanejos - que homem e artista se coadunam, que tradição e modernidade confluem. Nessa linha tênue (se é que ela existe) que delimita onde termina um - homem - e inicia outro - artista - ou vice-versa, sabe-se da não vocação de ambos para o cerceamento. É quando sua alma e seu corpo gritam.

É assim que Hugo Tavares Dutra, radicado na mesma Santa Cruz-RN que deu abrigo a Dona Eudóxia Ribeiro, constrói sua labuta artística. Poeta, compositor, esse paraibano, nascido em Brejo do Cruz, no ano de 1956, foi levado para morar em Catolé do Rocha aos dois anos de idade, onde passou sua infância e adolescência. Aí, forjou-se na arte. A música começou lá em Catolé do Rocha, nas feiras. Ouvindo embolador de coco, violeiros; ouvindo cantadores de feira, repentistas; ouvindo a rádio Alto Piranhas, de Cajazeiras; ouvindo a Rádio Rural de Caicó, a rádio Difusora de Mossoró. Os meus primeiros contatos com música foram esses.

Por adoção "potiguano", neologismo por ele criado, por meio do qual assume sua identidade potiguar, percebe-se não como um artista, mas como "uma pessoa comum, um cidadão, preocupado com a juventude, principalmente; com o Brasil; com a educação; com a saúde". Viu na arte o instrumento com que foi se "botando" no seu espaço, na sua comunidade. Prova disso é sua cartilha em cordel "Eu voto. Tu votas. Ele(a)s se elegem", fruto do seu projeto "Cidadania e Eleição", que inclui, além da cartilha, um CD intitulado "A fábula da formiga errante", no qual os temas da política são abordados nos vários gêneros musicais, do bolero, passando pelo coco até o baião.

Em que pese seu discurso "eu não me defino como artista", evidenciando uma suposta inconsciência do seu próprio fazer, o seu processo de criação artística, no entanto, revela não a "pessoa comum", mas o artista profundamente preocupado com sua produção. Eu mesmo não concebo o artista naquela história do trabalho - eu faço a música e vou vender... Eu nunca dei uma música minha a ninguém! Nem vou dar! Porque eu faço com um amor tão grande que aquilo é como se fosse um pedaço meu que vai - afirma convicto.

Admirador incondicional e pesquisador da obra e da vida de Fabião das Queimadas, a quem rendeu homenagem com a composição "Fabião das Queimadas: poeta da liberdade", Hugo Tavares é um artista que caminha na esteira da tradição musical nordestina - no coco, no baião, no xote, na embolada - temperada pela estética da música de protesto. Reconstrói sua temática com os elementos da realidade cotidiana, especialmente naquilo que toca o cultural, o social e o político. Como analisa o próprio Hugo, na música não tem mais nada de novidade. Novidade na música é quando você pega um texto e nele você tem alguma coisa nova para ser dita. Mas na musicalidade já fizeram tudo.

Para Hugo, o novo está ancorado no teor libertário que perpassa toda sua produção. E, logicamente, habitar uma região profundamente marcada pela política dos coronéis (o que já lhe 
rendera uma prisão por ousar montar uma rádio comunitária), conduz-Ihe a garimpar as imagens que poderão romper as várias formas de grilhões.

A arte, por mais simples que ela seja, desde que contextualizada para o soerguimento do ser humano, principalmente, vai encontrar espaço em qualquer lugar. Cantar uns versos como 'Eu nunca vi constelação de patente/ orientar navegante/ nem dar luz a cantador' é muito forte, vai deixando alguma coisa na cabeça de alguém e estimulando a quem está entrando nessa seara a cuidar para que a obra dele não seja descartável, banalizada. Então, se você como cidadão, tiver consciência do mundo, do que você pode contribuir, pode, através da arte, ser um instrumento desse.

Sendo o próprio Hugo Tavares instrumento da arte, nestes versos de sua canção "Rebento potiguano", por meio da metonímia sintetiza a condição de existência para todo artista: não abrir mão de sua identidade e de sua autonomia:

\author{
"O meu sotaque \\ é daqui é soberano \\ O meu eu é soberano \\ É de pedra e de pó."
}

Porém, não é apenas o sertão do agora essa zona de fronteira em que os ecos do passado se revitalizam nos limites de um presente que exige novas respostas e roupagens para antigas tradições. O projeto do Portal que iniciou em Santa Cruz acabou expandindo-se para o IFRN Zona Norte e iniciou um trabalho similar ao que havia sido organizado no Trairi, desta vez nas cidades do entorno da grande Natal, como Ceará Mirim e São Gonçalo.

Nas proximidades da umidade litorânea, as danças populares trazem elementos da tradição, sendo passíveis de ressignificações no contexto cultural presente. Os movimentos da dança surgem em prol dos movimentos sócio-afetivos-culturais dos dançantes, em diálogo com o imaginário popular da tradição e as questões da contemporaneidade. O desenvolvimento do processo imaginativo se dá pela percepção da relação entre a informação e as sensações, ou seja, os gestos, a memória e a percepção do mundo atual estão fortemente conectados. Os conhecimentos partilhados pela comunidade podem crescer através da invenção, da criação de metáforas gestuais que poetizam o cotidiano. É assim que se mantêm vivos os folguedos "Boi de Reis Pintadinho" e "Congo de Guerra do Mestre Tião".

O centenário Boi Pintadinho nasceu no Sítio Breu, na cidade de São Gonçalo do Amarante, às margens de um Potengi já cansado de guerra. Pelas mãos do Mestre Atanásio Salustino, essa dança de origem Ibérica, surgida provavelmente no século XV, profundamente ligada ao ciclo natalino, mantém- 
se viva e em busca de renovação. Chegando ao Brasil, ganhou traços particulares. No Nordeste, a história é baseada na saga do vaqueiro, em suas aventuras pelo sertão.

O Boi de Reis Pintadinho ganhou visibilidade quando estava sob o comando do Mestre Pedro Guagirú. Nessa época, o grupo teve participação de destaque no filme "Boi de Prata", do diretor Potiguar Augusto Ribeiro Júnior, filmado em Caicó, Natal e Rio de Janeiro, produzido e distribuído pela EMBRAFILME.

Ao conversarmos com os atuais brincantes, agora comandados pelo Mestre Dedé Veríssimo, pudemos perceber que eles convivem com essa manifestação cultural desde meninos. Em São Gonçalo, era comum os pais levarem seus filhos para feiras populares onde, sentadas em caixotes, as crianças podiam ver de perto a performance de artistas das mais diversas áreas: cantadores, sanfoneiros, ceramistas, louceiros, santeiros, mamulengueiros. Também iam atrás do Boi de Reis, dos Pastoris e Bambelôs. Esses brincantes, hoje, em sua maioria, adolescentes, parecem não se dar conta das profundas transformações ocorridas na representação do Boi de Reis Pintadinho.

Muitos sentem que as mudanças no velho ritual, derivado de um entorno marcado pela ruralidade, que durava de dez a doze horas de música, dança, bebida e comida, são perdas irreparáveis do Boi. No entanto, o interesse da comunidade, especialmente, das crianças pelo folguedo mostra que é possível repensar o lugar do Boi em um contexto contemporâneo, marcado pela urbanidade e pelo advento de novas formas de vida, cercadas pelo contato de novas mídias e de novas informações cênicas, poéticas e musicais.

Antes de preservarem o Boi como uma reminiscência, congelada em um molde folclorístico, marca morta de um mundo que se decompôs com o advento da urbanidade e das sociedades globalizadas, o Boi Pintadinho aponta para outro espaço da tradição do Boi de Reis em nosso Estado.

O Congo de Guerra do Mestre Tião, da comunidade Tabuão, em Ceará Mirim/RN, vem sendo apresentado desde trezentos anos passados. É uma espécie de teatro cujo espectador precisa imaginar o cenário evocado, os reinos africanos de outrora: os reis orgulhosos e seus fiéis guerreiros. Todos os personagens assumem papéis dramáticos. A narrativa se dá a partir de temas religiosos e temas sociais como o amor, a escravidão, o trabalho e os costumes antigos.

Embora existam diversificações no enredo, variando de região para região, levando a se criar sinônimos tais quais congo (s), congada (s), pretinhos-do-congo, etc., em todos estes é possível identificar as suas raízes formadoras (embaixadas e nações africanas), mantendo-se o mesmo fio condutor, as características gerais que permitem identificar o folguedo como um Congo.

Desde o Brasil colônia, elegia-se entre os negros um rei e uma rainha, cargos honorários, aceitos pela Igreja e apoiados pelos senhores escravocratas. $O$ régio casal de negros era escoltado por seus companheiros de senzala até a igreja onde acontecia a coroação, com muita música e dança. Estas, por sua vez, variavam de acordo com as etnias africanas e influências regionais. Rufas, rabecas e maracás fazem o fundo musical, juntamente com as cantigas que ora são toadas de viagens, ora louvores à Virgem do Rosário (Nossa Senhora do Rosário) ou louvações ao nascimento do Messias e, em muitos momentos, cantos de chamadas de atenção aos moradores do lugar. Há também a 
presença de cantigas de possível inspiração totêmica e cantares lúdicos irônicos. A variedade de peças cantadas é imensa e se sucedem até o momento da representação das embaixadas, ponto alto do folguedo.

Ao questionarmos alguns brincantes do Congo sobre a sua dança, obtivemos as seguintes respostas: Estamos perdendo uma batalha, o Congo de Guerra está morrendo. É preciso que a nova geração siga o exemplo do embaixador, cantando com emoção. Diz O mestre José Baracho, embaixador do Congo de Guerra e Poeta do Vale do Ceará Mirim. E acrescenta: A velha Taboão há de ser lembrada.

O mestre Tião (atual mestre do Congo de Guerra), hoje com 96 anos, nascido em Ceará Mirim, em 14 de maio, filho do antigo mestre João da Rocha, é morador, desde menino, da comunidade de Taboão, município dessa cidade, e trabalhador, por longos anos, do engenho da família Sobral. Alerta: "Um dia eu morrendo e também o grande José Severino (outro brincante), o grupo Congo perde roteiro, Ceará Mirim perde a cultura, ficando só uma lembrança obscura, de dois velhos bem nordestinos". Logo em seguida, o "embaixador" José Baracho acrescenta: Talvez se acabem os Congos guerreiros, mas as lutas dos dois Congueiros ficarão gravadas nesta cidade. Sendo indagado ao atual mestre, Seu Tião, sobre o que ele achava da possibilidade de outros grupos darem continuidade à brincadeira, e estes fazerem alterações na representação, ele respondeu: Pode mudar as vestimentas, o lugar onde se dança, acrescentar fatos, assim como eu mesmo fiz, ao receber o Congo de Taboão do meu pai; ouvi notícias no rádio sobre movimentos revolucionários da década de 30, e acrescentei elementos a este auto, mudando inclusive o nome, passando a se chamar "Congo de Guerra". No entanto, a jornada (passos da dança) tem que ser mantida, pois esses elementos é que mantêm a tradição.

Nesse diálogo, percebemos a preocupação dos mestres com o que diz respeito à continuidade da sua dança. Existe a consciência e o entendimento das transformações que aconteceram ou possam vir a acontecer, sem perder o fio condutor da narrativa, tendo em vista essa manifestação ser um auto e possuir uma espécie de estatuto que a diferencia de uma dança popular, a qual se apresenta de forma mais livre.

Vê-se bem que, dos sertões aos litorais, o Rio Grande do Norte não é mais um refúgio, um esconderijo cercado de serras e dunas, marcado pela presença de um mar oceano onipotente, que nos afastava do resto do mundo.

Os artistas potiguares, de nascimento ou de coração, que escolheram viver e produzir sua arte nesses sertões ou nesses litorais, consciente ou inconscientemente, sabem que vivem em uma zona de fronteira.

Mas não são geográficos esses limites. Não são espaciais essas trincheiras. A zona de fronteira de nossos sertões do agora e de nossos litorais contemporâneos é uma zona de convergência temporal, em que o eco de uma memória coletiva que habita o corpo, a voz ou a linguagem de nossos artistas, tenuamente se mistura com as reverberações de um mundo em violenta e constante transformação. 


\section{METODOLOGIA}

O projeto de extensão do Portal de Cultura Potiguar, coordenado pelos autores deste artigo, tem como intuito fundamental mapear os principais agentes culturais em atuação na região do Trairi e no entorno da Grande Natal. Após a primeira fase do mapeamento concluído, foram realizados registros audiovisuais de depoimentos de artistas da região.

Criou-se um portal, que pode ser acessado pelo endereço http://www2.ifrn.edu.br/culturapotiguar/ com o objetivo de construir uma rede que permita a divulgação e a disponibilização dos registros audiovisuais dos agentes culturais e artistas que atuam no interior do Rio Grande do Norte, fornecendo uma visão descentralizada da sua produção cultural, permitindo que sejam construídas novas formas de percepção e integração das comunidades que compõem as diversas regiões do Estado, e que seja experimentada uma nova forma de integração das diversas identidades regionais a partir de um modelo semiológico descentralizado e focado na própria comunidade e em suas expressões culturais mais profundas.

O projeto do Portal de Cultura Potiguar tem como objetivo fundamental o de permitir que os próprios artistas falem sobre seu trabalho, do modo mais livre possível, sem um filtro ideológico que Ihe seja imposto a partir da atuação dos próprios pesquisadores.

O Portal foi desenvolvido com utilização do Wordpress, um sistema de gerenciamento de conteúdo na web, que utiliza a linguagem de programação PHP e funciona com o banco de dados MySQL. O Wordpress é uma das ferramentas de criação de blogs/sites mais utilizadas na internet. Foi criado por Ryan Boren e Matthew Mullenweg, é distribuído sob a GNU General Public License, sendo, assim, gratuito. A escolha da sua utilização foi principalmente pela flexibilidade e rapidez no desenvolvimento do Portal, visto que, com o Wordpress, em pouco tempo conseguimos criar o Portal, já com a identidade visual modificada e diversas outras funcionalidades de interação, como a integração com as redes sociais, a exemplo de Facebook, Twitter, e com o canal do Portal no Youtube. Outro ponto positivo é a facilidade na postagem das entrevistas, pois o Wordpress já contempla uma área administrativa para a adição dos conteúdos.

Abaixo, segue a Figura 01, que ilustra a página inicial do Portal. Perceba que, de início, temos um mapa que destaca os Campi do IFRN, e clicando em um dos campi, iremos obter informações sobre o campus específico e as manifestações culturais na sua região de atuação. 


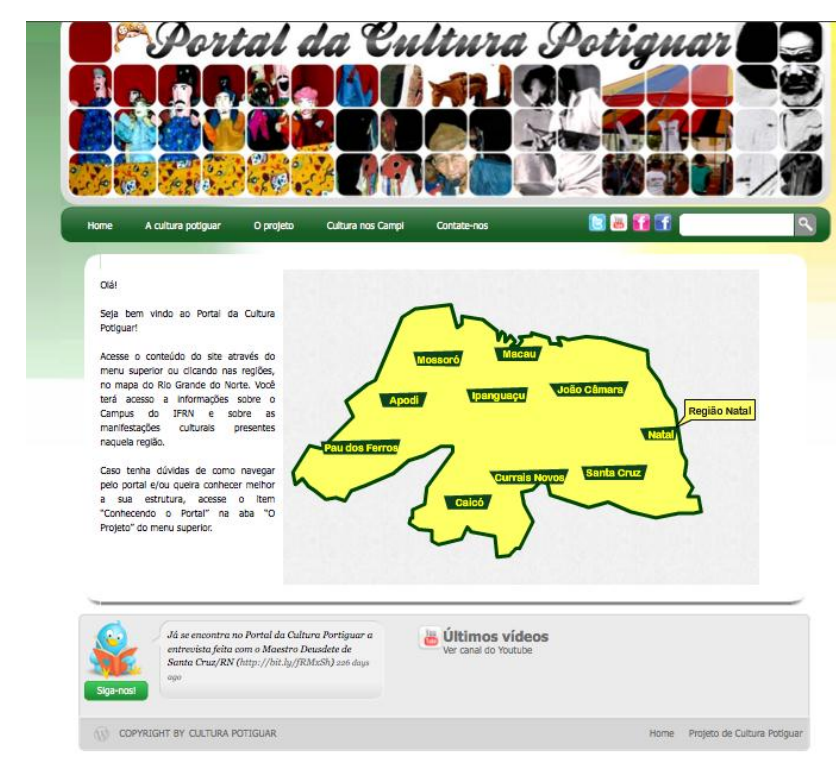

Figura 01 - Página inicial do Portal da Cultura Potiguar

A Figura 02 ilustra a página referente ao Campus de Santa Cruz/RN. Perceba que estão listadas entrevistas de manifestações culturais na área de atuação do Campus, e, clicando em uma delas, teremos acesso às entrevistas. Atualmente, já temos seis entrevistas relacionadas ao campus de Santa Cruz/RN.

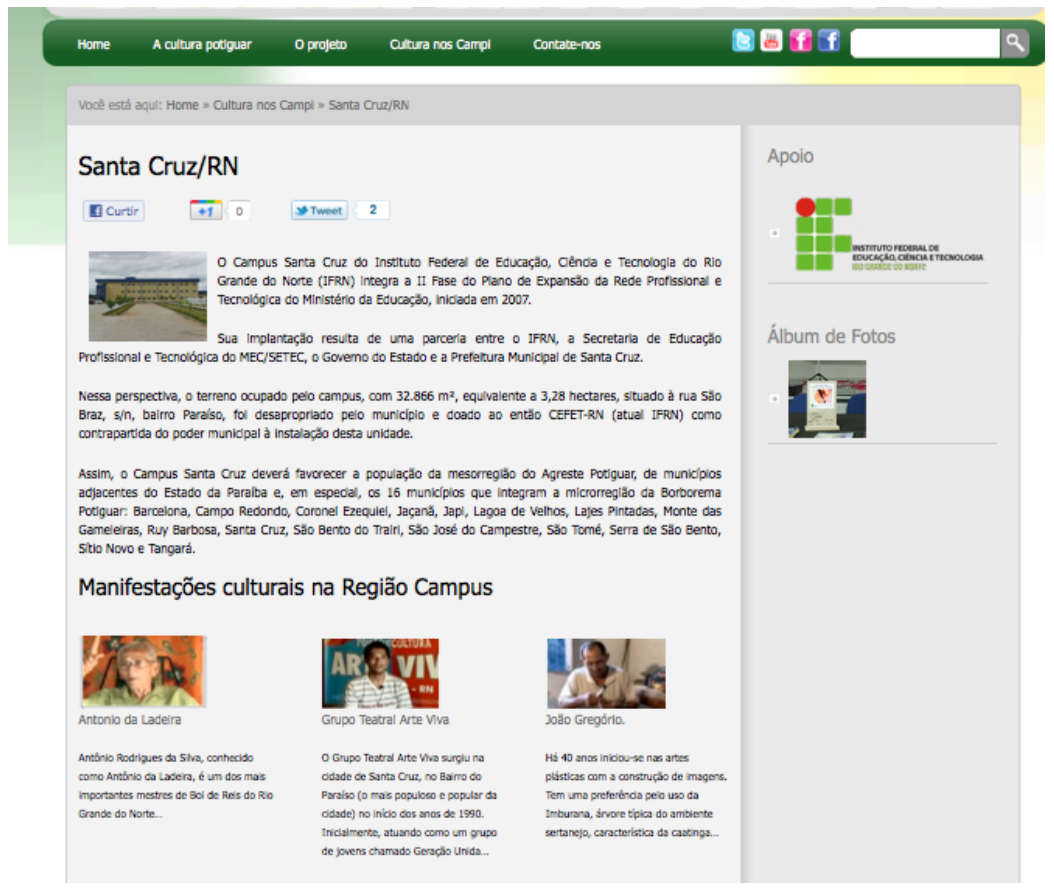

Figura 02 - Página referente ao Campus Santa Cruz. 
A Figura 03 ilustra a página da entrevista com Antônio Rodrigues da Silva, conhecido como Antônio da Ladeira, um dos mais importantes mestres de Boi de Reis do Rio Grande do Norte. O mestre Antônio foi tombado como Patrimônio Imaterial da Cultura Potiguar. Perceba que a entrevista foi divida em textos seguidos de vídeos, para melhorar a compreensão da entrevista e o texto se tornar mais atrativo e dinâmico. Lembramos que todos os vídeos estão no canal do Youtube do Portal, www.youtube.com/culturapotiguar, o que aumenta a abrangência do projeto em termos de divulgação da cultura potiguar. Outro ponto positivo é a integração do Portal com as redes sociais. No canto superior das entrevistas já existe a possibilidade de enviar para as redes sociais o link para a entrevista a que se tem acesso.

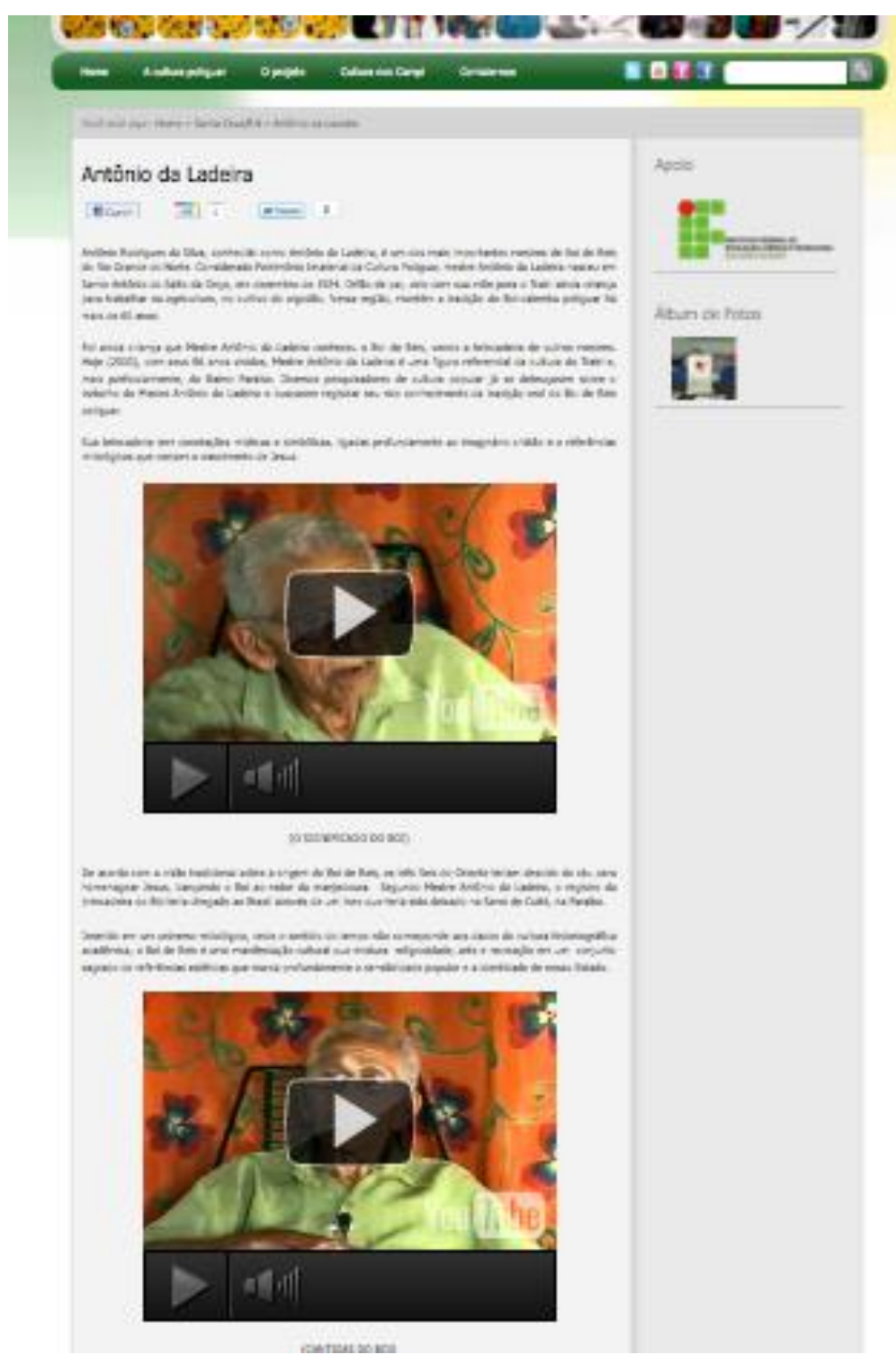

Figura 03 - Página da entrevista com Mestre Antônio da Ladeira

O Portal está em constante mudança, a fim de melhor divulgar a cultura potiguar na internet. Nele, já estão sendo feitos vários aperfeiçoamentos para ter melhorias no aspecto da acessibilidade dos conteúdos e uma maior interatividade, principalmente com a adição de uma agenda de eventos 
que estejam no contexto da cultura potiguar. Outras melhorias serão feitas nas redes sociais, visto que são temas mais atrativos para o Facebook e Twitter, a fim de se divulgar o projeto.

Uma vez posto no Portal, o material produzido a partir das entrevistas com os artistas se propõe a dar a conhecer ao aluno do Ensino Médio, a pesquisadores e a demais interessados na temática, a produção cultural do Rio Grande do Norte que se constrói à margem dos projetos governamentais e da divulgação midiática.

\section{ANÁLISE E INTERPRETAÇÃO DOS DADOS}

A internet, por ser uma rede, permite que se construa outro tipo de integração, sem um polo definido e sem um centro determinado que irradia a informação para outros polos em um esquema de "centro-periferia". Nesse sentido, o uso das redes sociais pode ser um elemento importante no que diz respeito à desconstrução de um modelo de produção de identidade cultural capitaneado por um centro irradiador. $\mathrm{O}$ uso da internet como ferramenta de integração das diversas regiões do Rio Grande do Norte diferencia-se substancialmente do fenômeno percebido nos anos de 1980 do século passado. A integração cultural patrocinada pela TV, em função de suas especificidades semiológicas, produziu um fenômeno de centralização cultural na região da Grande Natal, que atuou como síntese e catalisador da tradicional fragmentação sociopolítica do Estado, retendo em sua própria evolução urbana, as marcas dos paradoxos e das ambiguidades que construíram a história do Rio Grande do Norte.

Assim, com o advento das retransmissoras locais, o estado anterior de tripartição cultural foi quebrado e o Rio Grande do Norte começou a olhar "para dentro". No entanto, esse olhar está fundamentalmente vinculado à difusão cultural que irradia de uma capital em pleno estado de ebulição urbana e cultural, vinculada a uma crise na própria autoimagem psicossocial.

Esse tipo de integração cultural, capitaneada pelas velhas mídias, especialmente a TV, se baseia em um paradigma polarizador, em que um grande centro emite sua produção cultural, com os impasses e as ambiguidades que lhe são inerentes, para os polos do interior do Estado.

A ideia de se usar a internet e as redes sociais como veículo de divulgação e registro da produção artística e cultural do interior do estado do Rio Grande do Norte, capitaneada por um uso institucional de seus recursos, através de uma interação entre ensino, pesquisa e extensão no próprio IFRN, consiste em uma alternativa democrática e descentralizada de manter e expandir os elementos fundamentais que constituem a força motriz de uma identidade potiguar, sem que, para isso, seja propedêutica a construção de uma nova dicotomia que separe interior da capital, nem mesmo seja necessário oferecer de imediato uma solução para a crise de identidade cultural por que passa o Estado a partir de sua capital e do esgotamento de modelos teóricos de compreensão do povo e da cultura popular como os que foram descritos no início deste artigo.

Outro elemento envolvido na produção do Portal da Cultura Potiguar diz respeito às práticas educativas do próprio Instituto. A educação, através da aprendizagem da cultura, nos faz pensar em um educar que transita necessariamente pelo passado, na criação do presente e na formação de novas 
perspectivas para o futuro. É necessário imprimir, nos formadores de opinião e nas novas gerações, a importância de se ter o passado como algo que pode colaborar para a compreensão do nosso modo de ser. E isso passa também pelo acesso à produção artística potiguar, especialmente a do artista que, longe dos holofotes midiáticos, são extremamente importantes para a manutenção da tradição e da identidade cultural, ao mesmo tempo em que vão incorporando, a essa tradição, os elementos da modernidade que são assimilados no seu próprio cotidiano. Este que se encontra recheado das informações de uma "sociedade em rede" (CASTELLS, 2008).

\section{CONCLUSÃO}

O projeto do Portal de Cultura Potiguar, em sua primeira fase de execução na região do Trairi, demonstrou ser possível a construção de outras ferramentas de integração cultural no Rio Grande do Norte a partir do uso de novas mídias e de um conceito de informação em rede que não repita o padrão centro-periferia marcado pela presença de velhas mídias como as TVs abertas. Os usos dessas tecnologias e o modelo de atuação e de mapeamento empregado no projeto também contornam perspectivas teóricas problemáticas sobre conceitos como "cultura popular", "povo", "identidade e memória". Atuando como um veículo de divulgação da produção artística e cultural do Estado, o Portal de Cultura Potiguar não se propõe a resolver os impasses teóricos derivados da crise em que o cascudismo caiu, na medida em que o eixo cultural do Estado moveu-se em direção a uma Natal cada vez mais urbana, industrial, aberta ao turismo e à influência de migrantes que chegam de diversas regiões do Brasil e do mundo.

O que pôde ser percebido a partir dos mapeamentos realizados no Trairi, com a contribuição fundamental de agentes culturais da cidade e alunos do IFRN, é que as expressões artísticas que frutificam no interior do Estado, a despeito das mitologias românticas de extermínio e resistência, continuam fortes e vigorosas, adaptando-se às novas realidades culturais e às demandas sócioeconômicas impostas pelo desenvolvimento urbano e industrial do Rio Grande do Norte.

A identidade e a memória potiguar são assim, reconstruídas e redefinidas pelos artistas do Estado não a partir de modelos românticos ideais, mas a partir das próprias experiências e demandas do presente, a partir da introdução de novos conteúdos e novas experiências vivenciais.

Antes de servir às ideologias de resistência e preservação nostálgica de reinos antigos, que provavelmente só existem na mente de autores fortes como Ariano Suassuna e Câmara Cascudo, os artistas potiguares com que o Portal da Cultura Potiguar até agora deparou mostram que fazem parte do seu próprio tempo e dialogam com esse tempo criativamente, sem medo de perder o fio da própria arte e os significados de sua própria e misteriosa identidade.

\section{REFERÊNCIAS}

1. ALBUQUERQUE JUNIOR, Durval Muniz de. O mundo é a aldeia, região e nação como espaços privilegiados nos estudos sobre cultura popular na península ibérica e no Brasil, no começo do século XX. In: Almir de Carvalho Bueno (ORG.) Revisitando a História do Rio Grande do Norte. Natal: Edfurn, 2009. p. 193 - 217. 
2. ARAÚJO, Douglas. A morte do Sertão antigo no Seridó: o desmoronamento das fezendas agropecuárias em Caicó e Florania. Natal: BNB dissertações, 2006.

3. AUGUSTO, José. Seridó. Rio de Janeiro: Borsoi, 1954.

4. BEZERRA, Paulo. Outras cartas dos Sertões do Seridó. Natal, Edição do Autor, 2004.

5. CASCUDO, Câmara. Viajando o Sertão. São Paulo: Global, 2009.

$6 . \quad$ C Contos Tradicionais do Brasil. São Paulo: Edusp, 1996.

7. Geografia dos Mitos Brasileiros. São Paulo: Edusp, 1983.

8. CASTELLS, Manuel. O poder da identidade. Tradução Klauss Brandini Gerhardt. 6 ed. (A era da informação: economia, sociedade e cultura; vol. 2). São Paulo: Paz e Terra, 2008.

9. DAMASCENO, Eudóxia Ribeiro. As tramas da família Baianos. Santa Cruz: Supercópia Gráfica, 2006.

10. FARIA, Juvenal Lamartine de. Velhos costumes do meu sertão. Natal: Sebo Vermelho/Coleção Mossoroense, 2006.

11. GÓES, Moacyr de. De Pé no Chão Também se Aprende a Ler (1961-64) - Uma escola democrática. Rio de Janeiro: Civilização Brasileira, 1980. (Coleção Educação e Transformação - vol. 3).

12. GRONDIN, Jean. Introdução à hermenêutica filosófica. Tradução Benno Dischinger. São Leopoldo: UNISIMOS, 2003.

13. LOPES, Fátima Martins.Ordem e disciplina na construção do espaço urbano das vilas dos índios do Rio Grande (século XVIII). In: Almir de Carvalho Bueno (ORG.) Revisitando a História do Rio Grande do Norte. Natal: Edfurn, 2009. p. 53 - 83.

14. MACEDO, Helder Alexandre Medeiros de. Histórias indígenas no sertão do Seridó (séculos XVI XX). In: Almir de Carvalho Bueno (ORG.) Revisitando a História do Rio Grande do Norte. Natal: Edfurn, 2009. p. $13-52$.

15. MEDEIROS, Tarcísio. Aspectos geopolíticos e antropológicos da história do Rio Grande do Norte. Natal: Imprensa Universitária, 1973.

16. MELLO, José Octávio de Arruda. História da Paraíba: lutas e resistência. João Pessoa: União, 2002.

17. PEDREIRA, Flávia Sá. Natal era só festa? - confronto de identidades durante a segunda guerra. In: Almir de Carvalho Bueno (ORG.) Revisitando a História do Rio Grande do Norte. Natal: Edfurn, 2009. p. $219-242$.

18. RODRIGUES, Wagner do Nascimento. Potengi: fluxos do rio salgado no século XIX. Natal: Sebo Vermelho Edições, 2003.

19. TAVARES, Hugo. Eu voto. Tu votas. Ele(a)s se elegem. Santa Cruz, 2010. Projeto Cidadania e Eleição.

20. TINHORÃO, José Ramos. Pequena história da música popular (da modinha à canção de protesto). Petrópolis: Vozes, 1974.

21. TINHORÃO, José Ramos. História social da música popular brasileira. 2 ed. São Paulo: Editora 34, 2010.

22. TRINDADE, Sérgio Luiz Bezerra. Introdução à História do Rio Grande do Norte. Natal: Sebo Vermelho, 2007. 